\title{
Subarachnoid hemorrhage secondary to Brucella-induced cerebral aneurysm: a case report
}

\author{
Yanyan Guan ${ }^{1 \dagger}$, Nannan $\mathrm{Xu}^{2 \dagger}$, Yongyuan $\mathrm{Yao}^{3}$, Feng Zheng ${ }^{2}$, Fengzhe Chen ${ }^{2}$, Wei Wang ${ }^{4}$, Xiaomeng Dong ${ }^{2}$ and \\ Gang Wang ${ }^{2^{*}}$ (D)
}

\begin{abstract}
Background: Brucellosis is a common zoonotic disease that is prevalent in many areas worldwide. This infectious disease can occasionally affect the central nervous system but intracranial arteries are rarely involved.

Case presentation: A 17-year-old female who had a history of recurrent fever for 1 month was admitted for subarachnoid hemorrhage due to cerebral aneurysm rupture. Surgery was performed to fix the aneurysm, but the patient had persistent fever after the surgery. Cerebrospinal fluid testing showed a high white blood cell count and elevated protein level but no pathogen was identified in the first two tests. Brucella melitensis was identified in the third cerebrospinal fluid culture, and a diagnosis of brucellosis was finally rendered. The patient was subsequently treated with anti-Brucella medications and her symptoms improved significantly at the last follow-up.
\end{abstract}

Conclusion: Although extremely rare, Brucella-induced cerebral aneurysms can occur and this should be considered in the differential diagnosis of cerebrovascular accidents, especially in Brucella epidemic areas.

Keywords: Brucella, Cerebral mycotic aneurysm, Subarachnoid hemorrhage, Case report

\section{Background}

Brucellosis is one of the most prevalent zoonoses and is caused by Brucella species infection. Brucella has the ability to escape host immune surveillance; thus, Brucella can affect any organ system, and infection with Brucella tends to be chronic and persistent [1,2]. The incidence of nervous system involvement is rare in brucellosis, approximately $3-5 \%[3,4]$. The clinical presentation of neurobrucellosis is diverse and includes meningitis, meningoencephalitis, myelopathy, polyradiculitis, and mononeuritis [5, 6]. Blood vessels in the nervous system can occasionally be involved, and the presentation

\footnotetext{
* Correspondence: wangg1975@hotmail.com

†Yanyan Guan and Nannan Xu contributed equally to this work.

${ }^{2}$ Department of Infectious Disease, Qilu Hospital, Cheeloo College of

Medicine, Shandong University, Jinan 250012, Shandong, China

Full list of author information is available at the end of the article
}

of vasculitis range from mild inflammation to necrosis with a rare possibility of cerebral aneurysm formation [7].

The diagnosis of neurobrucellosis is based on microbiological evidence of cerebrospinal fluid (CSF), including the isolation of pathogens and the detection of specific antibodies. Although positive culture of Brucella is the gold standard for the diagnosis of brucellosis, according to previous studies $[6,8]$, only approximately $15 \%$ of brucellosis cases are diagnosed through the identification of Brucella in CSF culture.

Aneurysm formation as a manifestation of neurobrucellosis is rare and subarachnoid hemorrhage caused by Brucella-related aneurysm rupture is even rarer [8]. Here, we report, to our knowledge, the first case of CSFculture-confirmed Brucella-induced cerebral aneurysm in a patient, who developed subarachnoid hemorrhage.

(c) The Author(s). 2021 Open Access This article is licensed under a Creative Commons Attribution 4.0 International License, which permits use, sharing, adaptation, distribution and reproduction in any medium or format, as long as you give appropriate credit to the original author(s) and the source, provide a link to the Creative Commons licence, and indicate if changes were made. The images or other third party material in this article are included in the article's Creative Commons licence, unless indicated otherwise in a credit line to the material. If material is not included in the article's Creative Commons licence and your intended use is not permitted by statutory regulation or exceeds the permitted use, you will need to obtain permission directly from the copyright holder. To view a copy of this licence, visit http://creativecommons.org/licenses/by/4.0/ The Creative Commons Public Domain Dedication waiver (http://creativecommons.org/publicdomain/zero/1.0/) applies to the data made available in this article, unless otherwise stated in a credit line to the data. 


\section{Case presentation}

A 17-year-old girl passed out suddenly and was admitted to the emergency room of a local hospital. She presented with persistent fever for 1 month before admission, with headache, fatigue, arthralgia, myalgia and sweating. The overall past medical history was negative, with no family history of hypertension or cardiovascular diseases. An acute computed tomography (CT) scan showed subarachnoid hemorrhage in the left fissure and cistern (Fig. 1).CT angiography demonstrated an aneurysm in the M2 segment of the left middle cerebral artery (Fig. 1). Emergency surgery was performed and the aneurysm rupture was fixed by clipping. After the surgery, the patient had persistent fever. Intravenous cefuroxime $(3.0 \mathrm{~g} \mathrm{q} 12 \mathrm{~h})$ was empirically administered for 2 weeks, but the patient's condition did not improve. The patient was transferred to our department for further management.

Neurological examination was notable for positive right pathological reflexes, including Babinski's sign, Chaddock's sign, Hoffmann's sign and Kerning's sign. In addition, the patient had aphasia. Her parents denied a history of infectious diseases or contact with livestock. Laboratory studies showed an elevated erythrocyte sedimentation rate (ESR), at $64 \mathrm{~mm} / \mathrm{h}$ (normal range $0-20$ ), and mildly elevated liver enzymes, whereas other blood testing parameters, including complete blood counts, Creactive protein, procalcitonin, creatine, antinuclear antibodies, etc., were within normal ranges. Blood bacterial culture was negative. Abdominal CT scan revealed mild splenomegaly.

Given the negative blood culture and potential infectious aetiology, we performed lumber puncture (LP) to obtain CSF for further examination. Her intracranial pressure was elevated at $320 \mathrm{mmH}_{2} \mathrm{O}$ (normal range 80-180 $\mathrm{mmH}_{2} \mathrm{O}$ ). The appearance of CSF was cloudy with 118 white blood cells $/ \mathrm{mm}^{3}$ (lymphocyte predominance), protein $1.37 \mathrm{~g} / \mathrm{L}$, chloridion $123 \mathrm{mmol} / \mathrm{L}$, and glucose
$2.07 \mathrm{mmol} / \mathrm{L}$. Detailed results of the CSF test are shown in Table 1. An advanced diagnostic workup, including CSF cultures for bacteria, fungi and tuberculosis (TB) and polymerase chain reaction for virus, bacteria and TB,was performed without any positive findings (see Table 2). Based on the CSF results, bacterial infection of central nervous system (CNS) was considered and intravenous ceftriaxone $(2.0 \mathrm{~g} \mathrm{qd})$ was prescribed empirically.

After 10 days of treatment, fever resolved and the clinical status of the patient improved. She could communicate with simple words, and her neurological status improved slightly. A second LP with CSF analysis was performed, and the results of the CSF test were similar to those of the previous ones (see Table 1), with a negative result for bacterial culture. Autoimmuneencephalitis-specific antibodies, including anti-glutamate receptors, anti- $\gamma$-aminobutyric acid B receptor, leucinerich glioma inactived-1 and contacin-associated protein2, were all negative. A re-examination of blood revealed a decreased ESR, at $10.0 \mathrm{~mm} / \mathrm{h}$, and other laboratory studies (routine blood parameters, liver-enzymes, procalcitonin, etc.) were negative. The patient was referred to the rehabilitation department for the start of her rehabilitation.

Twenty-five days after the second LP, the patient's symptoms worsened. She developed fever again, and her body temperature fluctuated from $37.3^{\circ} \mathrm{C}$ to $38.2^{\circ} \mathrm{C}$, accompanied by nausea and vomiting. Neurological examination found neck stiffness. A complete blood count showed a total white blood cell count of $3.75 \times 10^{9} / \mathrm{L}$, with $34 \%$ neutrophils and $60.3 \%$ lymphocytes. Magnetic resonance imaging of the brain showed multiple infarction lesions accompanied by regional cerebral cortex necrosis on the left side of the brain. A third LP with CSF analysis was performed, and CSF culture was repeated. This time, the organism Brucella melitensis was identified. Given the positive culture, Brucella
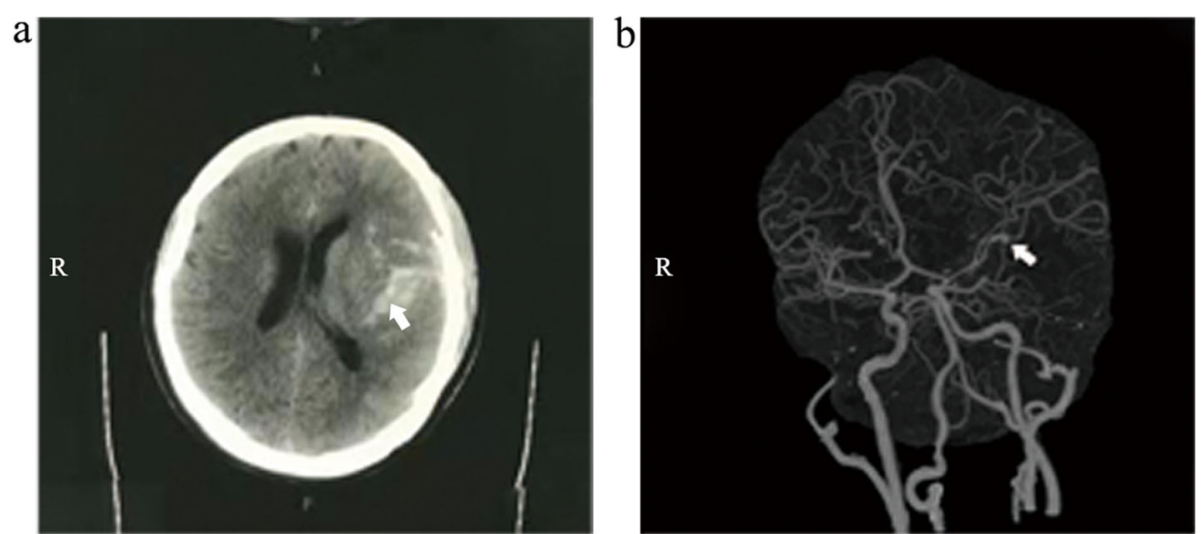

Fig. 1 CT and angiography of the patient's brain. An axial CT scan of the head showed signs of subarachnoid hemorrhage in left fissure and cistern (panel $\mathbf{a}$, white arrow). CT angiography illustrated an aneurysm in M2 segment of the left middle cerebral artery (panel $\mathbf{b}$, white arrow) 
Table 1 Cerebrospinal fluid analysis

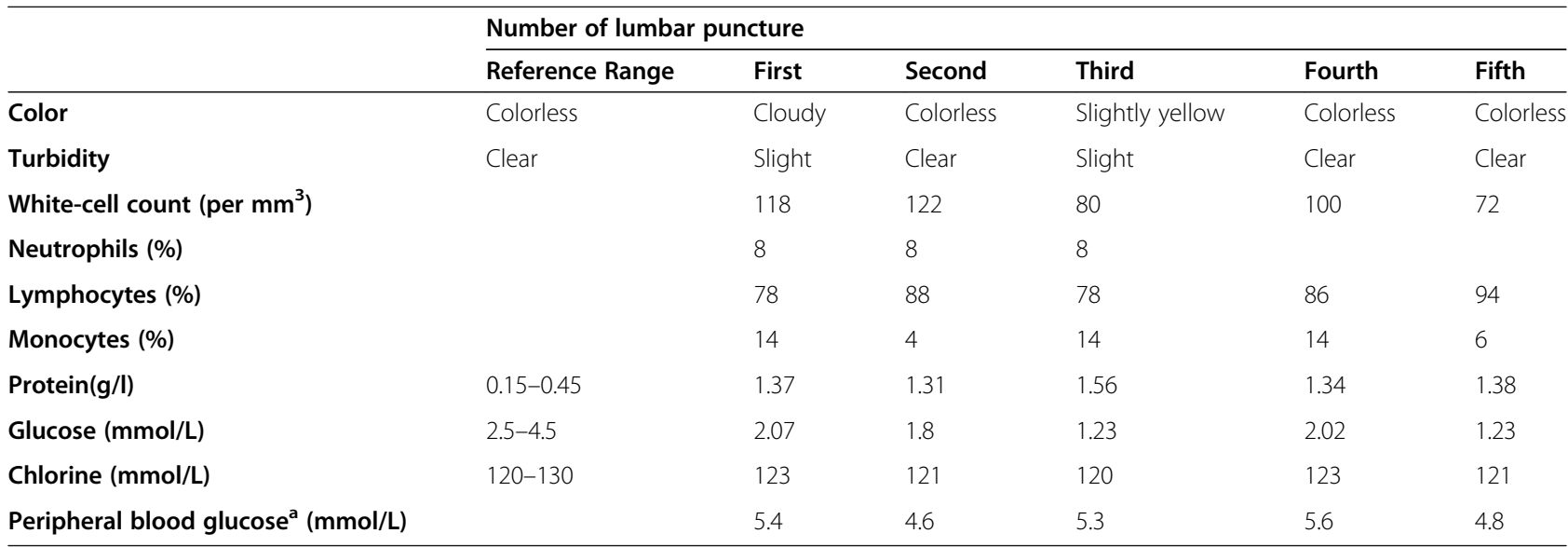

${ }^{\text {a }}$ Peripheral blood sugar corresponding to the glucose level in cerebrospinal fluid

Table 2 Results of microbiologic and serologic testing

\begin{tabular}{|c|c|}
\hline Variable & Result \\
\hline \multicolumn{2}{|l|}{ Cerebrospinal fluid } \\
\hline \multicolumn{2}{|l|}{ Cultures } \\
\hline Bacterium and Fungus & Brucella $^{\mathrm{b}}$ \\
\hline \multicolumn{2}{|l|}{ Molecular tests } \\
\hline Haemophilus influenzae & Negative \\
\hline Enterovirus & Negative \\
\hline Tuberculous bacillus & Negative \\
\hline Neisseria meningitidis & Negative \\
\hline Listeria monocytogenes & Negative \\
\hline Streptococcus pneumoniae & Negative \\
\hline Varicella-zoster virus & Negative \\
\hline Mumps virus & Negative \\
\hline Cytomegalovirus & Negative \\
\hline Mycoplasma pneumoniae & Negative \\
\hline Herpes simplex virus types 1 and 2 & Negative \\
\hline Epstein-Bar virus & Negative \\
\hline$J C$ virus & Negative \\
\hline Streptococcus agalactiae & Negative \\
\hline Acinetobacter baumannii & Negative \\
\hline Cryptococcus neoformans & Negative \\
\hline Human herpes virus type 6 & Negative \\
\hline Escherichia coli K1 & Negative \\
\hline \multicolumn{2}{|l|}{ Immunological Test } \\
\hline Brucella antibody & Positive $^{b}$ \\
\hline \multicolumn{2}{|l|}{ Blood } \\
\hline \multicolumn{2}{|l|}{ Cultures } \\
\hline Bacterium and Fungus & Negative \\
\hline \multicolumn{2}{|l|}{ Immunological Test } \\
\hline Brucella antibody & Positive \\
\hline
\end{tabular}

antibodies in serum and CSF were analysed by an enzyme-linked immunosorbent assay (ELISA) kit (IBL International $\mathrm{GmbH}$, Germany). A concentration of $\geq 12$ $\mathrm{U} / \mathrm{ml}$ was considered positive. The results were positive both in the serum (IgM $10.88 \mathrm{U} / \mathrm{ml} ; \mathrm{IgG}>150 \mathrm{U} / \mathrm{ml})$ and in the CSF (IgM $6.37 \mathrm{U} / \mathrm{ml}$; IgG>150 U/ml). Echocardiography showed no sign of endocarditis.

With the confirmed diagnosis of Brucella-related CNS infection, triple-agent therapy composed of intravenous doxycycline $(0.1 \mathrm{~g}$ bid) and ceftriaxone $(2.0 \mathrm{~g} \mathrm{qd})$ plus oral rifampin $(0.6 \mathrm{~g} \mathrm{qd})$ was administered. After 2 weeks of treatment, the patient's body temperature returned to normal. Other symptoms, such as nausea and vomiting were also relieved. A fourth LP was performed and showed that CSF Brucella-antibodies were IgM 4.37 U/ $\mathrm{ml}$ and IgG $>150 \mathrm{U} / \mathrm{ml}$. CSF culture showed no growth, as expected. The triple-agent regimen continued for 1 month, followed by the fifth LP, which showed that the level of CSF Brucella antibody IgM dropped to $1.49 \mathrm{U} /$ $\mathrm{ml}$ and IgG remained $>150 \mathrm{U} / \mathrm{ml}$. The patient had no fever, and all symptoms continued to improve. She was discharged and continued on treatment with oral doxycycline $(0.1 \mathrm{~g}$ bid) and rifampin $(0.6 \mathrm{~g} \mathrm{qd})$. At the last follow-up, 6 months after anti-Brucella therapy, the patient's condition had markedly improved and her speech recovered.

\section{Discussion and conclusions}

Neurobrucellosis is a rare complication of brucellosis, appearing in only $0.8 \%$ of cases of brucellosis in children [9]. Neurobrucellosis usually manifests as meningitis or meningoencephalitis. Cerebrovascular complications are rare, accounting for approximately $3 \%$ of neurobrucellosis $[10,11]$. Diagnosis may be secondary to acute cerebrovascular events and therefore delayed, resulting in permanent sequelae and even death $[6,12]$. 
However, the diagnosis of neurobrucellosis can be challenging. Neurobrucellosis has neither typical clinical manifestations nor special manifestations in CSF. Its discovery of neurobrucellosis is based on the existence of nervous system manifestations not explained by any other neurological disease, which may lead to a delay in the diagnosis of neurobrucellosis [13, 14]. In the case presented here, the patient had cerebrovascular accidents as the primary symptom and did not have a high risk factor for brucellosis; therefore, brucelosis was not considered in the initial diagnosis. Second, repeated administration of empirical antibiotics led the initial two sets of blood and CSF cultures to be negative. Given the absence of symptom improvement following empirical therapy, antimicrobial agents were discontinued, which may have been the reason for the detection of Brucella in the third CSF culture and the subsequent diagnosis of neurobrucellosis. A good clinical outcome of the appropriate medical treatment further supports the diagnosis.

Intracranial aneurysm formation and subarachnoid hemorrhage associated with brucellosis are very rare. According to our literature review, there are only 2 reported cases of subarachnoid hemorrhage due to Brucella-related aneurysm rupture $[15,16]$. The underlying mechanisms of Brucella-related cerebral aneurysm formation are unclear and may be multifactorial. The inflammation reaction can be induced by the bacteria themselves or by the endotoxins they produce and the cytokines they trigger. The inflammation subsequently cause the damage to the muscularis and adventitia of cerebral arteries. The elasticity of vessel walls decreases, and the vessels bulge under the pressure of blood flow to form an aneurysm $[3,15,17,18]$. Compared with aneurysms caused by other factors, infectious aneurysm progressed more rapidly and had a higher risk of rupture [19] . Although there is still controversy about the optimal treatment [20], dual- or triple-agent therapy should be initiated immediately upon diagnosis. Effective early treatment of brucellosis can prevent the development and rupture of aneurysms and improve the patient's neurological status $[15,16]$.

Early diagnosis and treatment can reduce the mortality and morbidity of neurobrucellosis [14]. Therefore, neurobrucellosis should remain in the differential diagnosis when patients come from endemic areas and present with nonspec ific neurological symptoms, even without a clear history of infectious exposure. Early diagnosis is highly critical for these patients to avoid permanent lethality $[14,21]$. Given the difficulty of Brucella cultivation, antibody detection is of great help especially in CSF [22] .

\section{Abbreviations}

CSF: Cerebrospinal fluid; CT: Computed tomography; ESR: Erythrocyte sedimentation rate; LP: Lumber puncture; TB: Tuberculosis; CNS: Central nervous system

\section{Acknowledgements}

The authors thank all the clinical and laboratory stuffs contributed in the case.

\section{Authors' contributions}

Material preparation, data collection and analysis were performed by $Y G, Y Y$, FZ and FC. The first draft of the manuscript was written by NX. WW, XD, GW edited and revised the manuscript. All authors read and approved the final manuscript.

\section{Funding}

No external funding.

Availability of data and materials

Not applicable.

\section{Declarations}

Ethics approval and consent to participate

This study was approved by Shandong University Qilu Hospital human research protection committee (IRB \# KYLL-2019-268).

\section{Consent for publication}

Written informed consent for publication from the patient and her parents was obtained.

\section{Competing interests}

The authors declare that they have no competing interests.

\section{Author details}

'Department of Infectious Disease, Rizhao People's Hospital, Rizhao 276800, Shandong, China. ${ }^{2}$ Department of Infectious Disease, Qilu Hospital, Cheeloo College of Medicine, Shandong University, Jinan 250012, Shandong, China. ${ }^{3}$ Department of Intensive Care Medicine, Rizhao People's Hospital, Rizhao 276800, Shandong, China. ${ }^{4}$ Department of Hematopathology, The University of Texas MD Anderson Cancer Center, Houston, TX 77030, USA

Received: 29 September 2020 Accepted: 1 July 2021

Published online: 31 July 2021

\section{References}

1. Franco MP, Mulder M, Gilman RH, Smits HL. Human brucellosis. Lancet Infect Dis. 2007:7(12):775-86. https://doi.org/10.1016/S1473-3099(07)70286-4.

2. Colmenero JDRJ, Martos F, Sánchez-De-Mora D, Delgado M, Causse M, Martín-Farfán A, et al. Complications associated with Brucella melitensis infection: a study of 530 cases. Medicine (Baltimore). 1996;75(4):195-211. https://doi.org/10.1097/00005792-199607000-00003.

3. Zheng R, Xie S, Lu X, Sun L, Zhou Y, Zhang Y, et al. A systematic review and meta-analysis of epidemiology and clinical manifestations of human brucellosis in China. Biomed Res Int. 2018;2018:5712920.

4. Buzgan T, Karahocagil MK, Irmak H, Baran Al, Karsen H, Evirgen O, et al. Clinical manifestations and complications in 1028 cases of brucellosis: a retrospective evaluation and review of the literature. Int J Infect Dis. 2010; 14(6):e469-78. https://doi.org/10.1016/j.ijid.2009.06.031.

5. Al Deeb SM, Yaqub BA, Sharif HS, Phadke JG. Neurobrucellosis:clinical characteristics, diagnosis, and outcome. Neurology. 1989;39(4):498-501.

6. Guven T, Ugurlu K, Ergonul O, Celikbas AK, Gok SE, Comoglu S, et al. Neurobrucellosis: clinical and diagnostic features. Clin Infect Dis. 2013;56(10): 1407-12. https://doi.org/10.1093/cid/cit072.

7. Fincham RW, Sahs AL, Joynt RJ. Protean manifestations of nervous system brucellosis. Case histories of a wide variety of clinical forms. JAMA. 1963;184: 269-75.

8. Adaletli IAS, Gurses B, Ozer H, Yilmaz MH, Gulsen F, Sirikci A. Vasculopathic changes in the cerebral arterial system with neurobrucellosis. AJNR Am J Neuroradiol. 2006:27(2):384-6.

9. Lubani MM, Dudin KI, Araj GF, Manandhar DS, Rashid FY. Neurobrucellosis in children. Pediatr Infect Dis J. 1989:8(2):79-82.

10. Rossi M, Tascini C, Carannante N, Di Caprio G, Sofia S, lacobello C. Neurobrucellosis: diagnostic and clinical management of an atypical case. New Microbiol. 2018;41(2):165-7. 
11. Gul HC, Erdem H, Bek S. Overview of neurobrucellosis: a pooled analysis of 187 cases. Int J Infect Dis. 2009;13(6):e339-43. https://doi.org/10.1016/j.jijd.2 009.02.015.

12. Ay S, Tur BS, Kutlay S. Cerebral infarct due to meningovascular neurobrucellosis: a case report. Int J Infect Dis. 2010;14(Suppl 3):e202-4. https://doi.org/10.1016/ji.jid.2009.07.012.

13. Budnik I, Fuchs I, Shelef I, Krymko H, Greenberg D. Unusual presentations of pediatric neurobrucellosis. Am J Trop Med Hyg. 2012;86(2):258-60. https:// doi.org/10.4269/ajtmh.2012.11-0468.

14. Turkoglu SA, Halicioglu S, Sirmatel F, Yildiz M, Yildiz N, Yildiz S. Vasculitis and neurobrucellosis: evaluation of nine cases using radiologic findings. Brain Behav. 2018;8(4):e00947. https://doi.org/10.1002/brb3.947.

15. Erdogan B, Sener L, Ozsahin K, Savas L, Caner H. An unusual case of ruptured distal anterior cerebral artery aneurysm associated with brucellosis. J Inf Secur. 2005;51(3)::79-82.

16. Kaya S, Velioglu M, Colak A, Kutlay M, Demircan MN, Tekin T, et al. Brucellarelated cerebral aneurysms/subarachnoidal hemorrhage: a short review featuring a case report. Neurosurg Rev. 2008;31(3):337-41. https://doi.org/1 0.1007/s10143-008-0136-6.

17. Akdeniz HIH, Anlar O, Demiröz AP. Central nervous system brucellosis: presentation, diagnosis and treatment. J Inf Secur. 1998;36(3):297-301.

18. Sullivan GWSI, Linden J. The role of inflammation in vascular diseases. J Leukoc Biol. 2000;67(5):591-602. https://doi.org/10.1002/jb.67.5.591.

19. Wilson WR, Bower TC, Creager MA, Amin-Hanjani S, O'Gara PT, Lockhart PB, et al. Vascular Graft Infections, Mycotic Aneurysms, and Endovascular Infections: A Scientific Statement From the American Heart Association. Circulation. 2016;134(20)

20. Pappas G, Akritidis N, Christou L. Treatment of neurobrucellosis: what is known and what remains to be answered. Expert Rev Anti-Infect Ther. 2007; 5(6):983-90. https://doi.org/10.1586/14787210.5.6.983.

21. Shakir RAA-DA, Araj GF, Lulu AR, Mousa AR, Saadah MA. Clinical categories of neurobrucellosis. A report on 19 cases. Brain. 1987;110(Pt 1):213-23. https://doi.org/10.1093/brain/110.1.213.

22. Baldi PCAG, Racaro GC, Wallach JC, Fossati CA. Detection of antibodies to Brucella cytoplasmic proteins in the cerebrospinal fluid of patients with neurobrucellosis. Clin Diagn Lab Immunol. 1999;6(5):756-9. https://doi.org/1 0.1128/CDLI.6.5.756-759.1999

\section{Publisher's Note}

Springer Nature remains neutral with regard to jurisdictional claims in published maps and institutional affiliations.

Ready to submit your research? Choose BMC and benefit from:

- fast, convenient online submission

- thorough peer review by experienced researchers in your field

- rapid publication on acceptance

- support for research data, including large and complex data types

- gold Open Access which fosters wider collaboration and increased citations

- maximum visibility for your research: over $100 \mathrm{M}$ website views per year

At $\mathrm{BMC}$, research is always in progress.

Learn more biomedcentral.com/submissions 